\title{
Development and evaluation of biodiesel fuel and by-products from jatropha oil
}

\author{
G. El Diwani, *N. K. Attia, S. I. Hawash \\ Chemical Engineering and Pilot Plant Department, National Research Center, Dokki, Egypt \\ Received 18 June 2008; $\quad$ revised 9 October 2008; accepted 27 December 2008; available online 1 March 2009
}

\begin{abstract}
Biodiesel is an environmentally friend renewable diesel fuel alternative. Jatropha seeds can be a feedstock to produce a valuable amount of oil to be converted to biodiesel using transesterification reaction. Jatropha plant has been successfully grown in southern Egypt using primary treated municipal wastewater for its irrigation. A bench scale production of biodiesel from Jatropha oil (using methyl alcohol and sodium hydroxide as catalyst) was developed with methyl esters yield of $98 \%$. Biodiesel was produced on a pilot scale based on the bench scale experiment results with almost the same methyl esters yield of $98 \%$. The produced biodiesel was evaluated as a fuel and compared with petroleum diesel according to its physical and chemical parameters such as viscosity, flash point, pour point, cloud point, carbon residue, acid value and calorific value. The experimental techniques and product evaluation results show that such properties of the produced biodiesel are near to that of petroleum diesel. A mass balance representing the transesterification process is presented in this study. Glycerol of $85 \%$ purity was produced and evaluated as a valuable byproduct of the process. Free fatty acids and sodium phosphate salts which have industrial interesting are also produced and evaluated.
\end{abstract}

Keywords: Transesterification, biofuel glycerol, methanolysis, fatty acids, pilot plant

\section{INTRODUCTION}

According to the environmental worries and the consumption of non-renewable natural energy resources, developing alternative resources of energy as a substitute of traditional fossil fuels has been risen. Biodiesel is among those alternatives and it is defined as an alternative fuel for diesel engines produced by chemically reacting a vegetable oil or animal fat with an alcohol such as methanol or mono-alkyl esters of long chain fatty acids derived from a renewable lipid feed stock, such as vegetable oil or animal fat (Ma and Hanna, 1999; Van Gerpen, 2005; Wang et al., 2006).

Vegetable oils were proposed as diesel fuels as they are widely available from a variety of sources and they are renewable (Boehman, 2005; Wan Nik et al., 2005). On the other hand, they were found to be problematic due to their greater viscosity which affecting piston, injector deposits and oil thickening (Baldwin et al., 1982; Fuls et al., 1984; Peterson et al., 1983; Ryan et al., 1984; Van Der Wat and Hugo, 1982). Conversion of the oils to their alkyl esters reduced the viscosity to near the diesel fuel levels and produced a fuel with properties that were similar to petroleum based diesel

凶*Corresponding Author Email: nahed_attia@yahoo.com Tel./Fax: +2 020162530561 fuel and which could be used in existing engines without modifications. The main advantages of using biodiesel fuels as $100 \%$ methyl or ethyl esters of vegetable oil and animal fat or biodiesel blends (up to $20 \%$ blend to the diesel fuel) are producing less smoke and particulates, having higher cetane numbers and producing lower carbon monoxide and hydrocarbon emissions (Antolin et al., 2002; Encinar et al., 2007). They also present some technical challenges such as low volatility, high pour and cloud points and cold filter plugging temperature. They contain essentially no sulfur; therefore, greatly reduce sulfur dioxide emissions from diesel vehicles (Alptekin and Canakci, 2008; Saifuddin and Chua, 2004; Vicente et al., 2004).

As an alternative to diesel fuel, biodiesel must be technically feasible, economically competitive, environmentally acceptable and readily available. Nowadays, biodiesel fuel is used in public traffic for performing farm engines, lighting and heating of rooms in specific conditions (Haas, 2005; Schlautman et al., 1986; Tomasevic and Siler Marinkove, 2003). However, biodiesel cost is higher than the oil-derived diesel due to the cost of virgin vegetable oil. Therefore, it is necessary to explore ways to reduce production cost 
of biodiesel. Minimizing the cost of raw materials is a special interest. There are a number of non-edible treebased oil seeds available (Kayasiri et al., 1996; Phan and Phan, 2008) in many countries around the world. Jatropha (Jatropha Curcas) is one of such non-edible oils cultivated in southern Egypt and irrigated with primary treated municipal wastewater. Using this non-edible oil for making biodiesel has a great opportunity of making it economically feasible (Tiwari et al., 2007). In addition, it helps in reducing the cost of advancing wastewater treatment.

Biodiesel produced by transesterification reaction can be catalyzed with alkali, acid or enzyme. Chemical catalyst processes, including alkali and acid ones are more practical compared with the enzymatic method. Alkali process can achieve high purity and yield of biodiesel product in a short time (Dorado et al., 2004; Meher et al., 2006a; Tiwari et al., 2007). Methyl or ethyl esters are the product of transesterification of vegetable oils with alcohol (methanol / ethanol) using an alkaline catalyst. In addition, the process yields glycerol which has great applications in the pharmaceutical, food and plastics industries (Bouaid et al., 2005; Meher et al., 2006b; Srivastava and Prasad, 2000). The purpose of this work is to study the development of biodiesel process at pilot plant scale using jatropha oil as the raw material with methanol and sodium hydroxide as the catalyst and evaluate the produced biodiesel as a fuel. This study has been carried out in National Research Center in Egypt during winter 2007.

\section{MATERIALS AND METHODS}

Materials

Jatropha oil used for the production of biodiesel on both bench and pilot scales by base catalyst transesterification was extracted at the National Research Center, Egypt. The oil composition and properties are reported in Table 1. Methanol of 99.8 $\%$ analytical reagent was used. The catalyst was sodium hydroxide purified pellets of $97 \%$ minimum assay.

Table 1: Fatty acids composition of used jatropha oil

\begin{tabular}{lc}
\hline Fatty acid & Composition (wt. \%) \\
\hline Palmitic (16:0) & 18.22 \\
Stearic (18:0) & 5.14 \\
Oleic (18:1) & 28.46 \\
Linoleic (18:2) & 48.18 \\
Avg. M. wt. & 874 \\
\hline
\end{tabular}

\section{Analytical methods}

Fatty acids composition of the used jatropha oil was determined using gas liquid chromatographic analysis of the oil ethyl esters. Modification of the oil to its ethyl esters was made using $2 \% \mathrm{H}_{2} \mathrm{SO}_{4}$ as catalyst in the presence of dry ethyl alcohol in excess. The chromatographic analysis was made using Hewlett Packard Model 6890 Chromatograph. A capillary column $30 \mathrm{~m}$ length and $530 \mu \mathrm{m}$ inner diameter packed with Apiezon ${ }^{\circledR}$ was used. Detector temperature, injection temperature and the column temperature were $280{ }^{\circ} \mathrm{C}, 300{ }^{\circ} \mathrm{C}$ and 100 to $240{ }^{\circ} \mathrm{C}$ at $15{ }^{\circ} \mathrm{C} / \mathrm{min}$, respectively. Purity of glycerol was determined using the HPLC Shimadzu LC 10 with a refractive index detector. The used column was Shim- Pack SCR-10N $(7.9 \mathrm{~mm} \times 30 \mathrm{~cm})$ (Shimadzu column). The mobile phase was water with flow rate of $0.5 \mathrm{~mL} / \mathrm{min}$ at $50^{\circ} \mathrm{C}$.

Biodiesel properties such as viscosity (Knothe and Steidley, 2005), flash point, pour point, cloud point, carbon residue, acid value and calorific value were carried out by Petroleum Institute at Egypt using ASTM standard methods.

\section{Bench scale experiment}

Biodiesel was produced based on bench scale by transesterification of jatropha oil according to the optimum reaction conditions obtained from laboratory study with maximum yield of $98 \%$ of methyl esters. Transesterification of $2 \mathrm{~kg}$ of jatropha oil was carried out in $4 \mathrm{~L}$ round flask placed in an adjusted temperature water bath. The reaction was performed using 6:1 molar ratio of alcohol to oil and catalyst concentration of $1 \%$ by weight of the oil at $65^{\circ} \mathrm{C}$ under reflux condenser with mechanical stirrer as illustrated in Fig. 1. After one hour reaction time, the reaction mixture was carefully transferred to a suitable separating funnel. Two layers were separated after about $6 \mathrm{~h}$; the upper layer is methyl esters and the lower one is the glycerol containing layer.

\section{Pilot scale process}

Transesterification of $100 \mathrm{~L}$ jatropha oil was carried out on the pilot scale with the same chemical conditions used in the bench scale experiment. The reaction was carried out in an enameled reactor of $150 \mathrm{~L}$ capacity equipped with an anchor stirrer and provided with temperature, pressure and stirring speed controllers. Jatropha oil was loaded to the reactor and preheated. The solution of the methanol and sodium hydroxide was prepared and added to the reactor. The reactants 


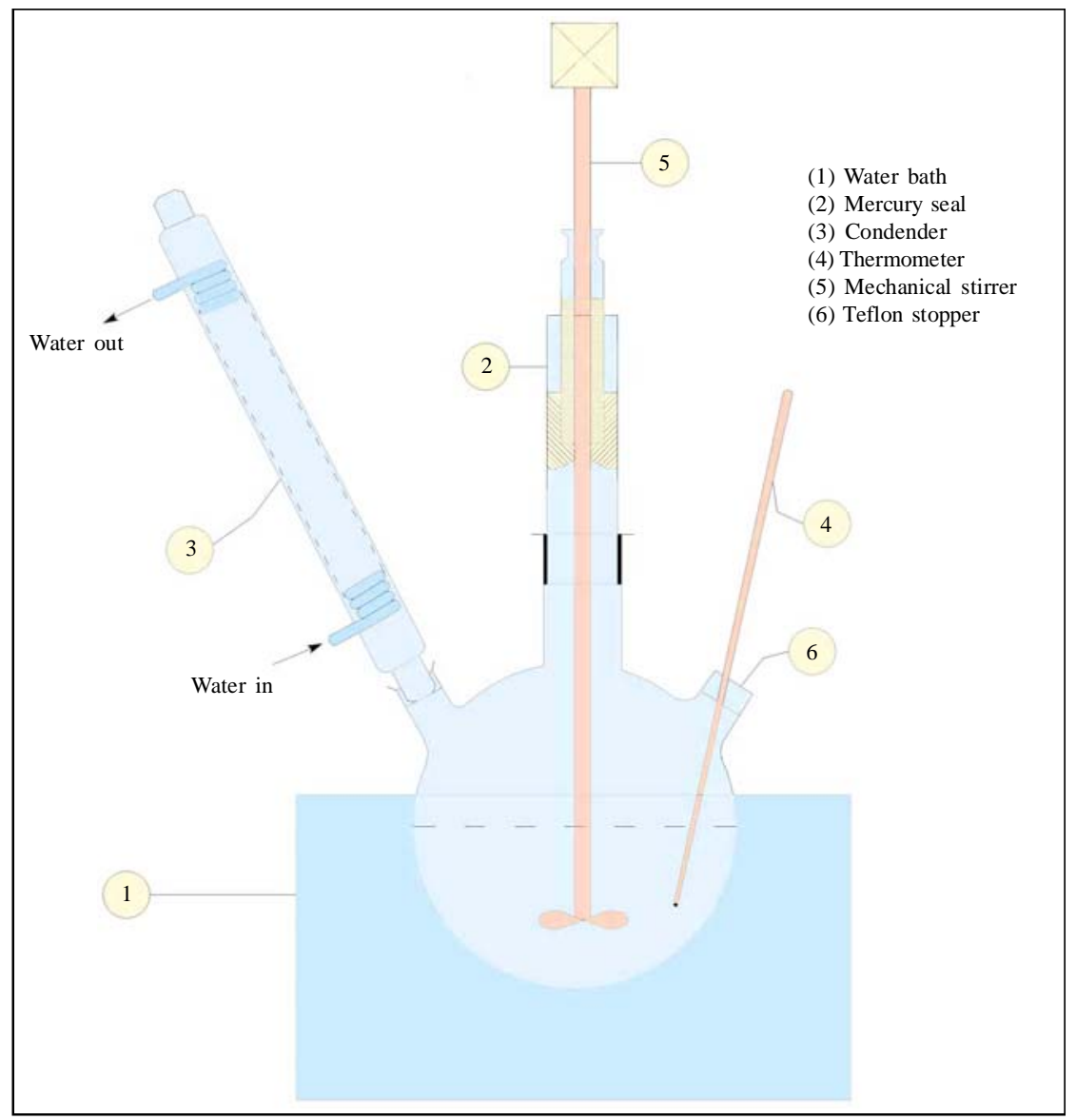

Fig. 1: Bench scale reactor

were agitated under fixed speed, constant temperature and atmospheric pressure for $60 \mathrm{~min}$. The reaction mixture was then transferred to a $200 \mathrm{~L}$ decanter. Two layers were distinguished separated after about $6 \mathrm{~h}$, the methyl esters is the upper layer where the lower one is the glycerol containing layer.

\section{RESULTS AND DISCUSSION}

Transesterification or alcoholysis is the displacement of alcohol from an ester by another in a process similar to hydrolysis, except that alcohol is used instead of water (Meher et al., 2006b; Srivastava and Prasad, 2000). This process is used to reduce the viscosity of triglycerides. Transesterification of triglycerides produces fatty acid alkyl esters and glycerol. The glycerol layer settles down at the bottom of the reaction vessel. Diglycerides and monoglycerides are the intermediates in this process. The mechanism of transesterification is described as follows:

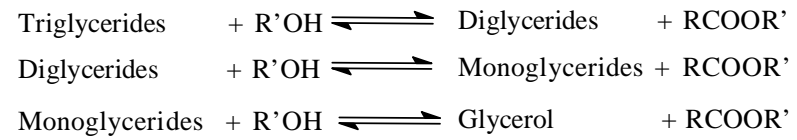

Mechanism of transesterification

When methanol is used for transesterification, $\mathrm{R}^{\prime}$ is $\mathrm{CH}_{3}$ and the process is called methanolysis. Methanolysis of jatropha oil requires three moles of methanol and can be represented by the following equation:

$$
\begin{aligned}
& \mathrm{CH}_{2}-\mathrm{OOC}-\mathrm{R}_{1} \quad \mathrm{R}_{1}-\mathrm{COO}-\mathrm{CH}_{3} \quad \mathrm{CH}_{2}-\mathrm{OH} \\
& \mathrm{CH}-\mathrm{OOC}-\mathrm{R}_{2}+3 \mathrm{CH}_{3} \mathrm{OH} \longrightarrow \mathrm{R}_{2}-\mathrm{COO}-\mathrm{CH}_{3}+\underset{\mathrm{CH}}{\mathrm{C}}-\mathrm{OH} \\
& \mathrm{CH}_{3} \text {-OOC- } \mathrm{R}_{1} \quad \mathrm{R}_{3}-\mathrm{COO}-\mathrm{CH}_{3} \quad \mathrm{CH}_{2}-\mathrm{OH} \\
& \begin{array}{cccc} 
& \text { Methyl } & \text { Methyl } & \\
\text { Triglycerides } & \text { alcohol } & \text { esters } & \text { Glycerol }
\end{array}
\end{aligned}
$$

Trasesterification of triglycerides 
Where, $R_{1}, R_{2}, R_{3}$ are three moles of the fatty acids constituents of jatropha oil which are recorded in Table 1. Methanolysis of jatropha fatty acids using $100 \%$ excess methanol to force the reaction to the forward direction, produced the corresponding fatty acids methyl esters and release glycerol.

\section{Biodiesel through bench scale}

The separated two layers of the reaction mixture were collected. The methanol was removed from the methyl esters layer and its weight was determined then the biodiesel yield was calculated based on the initial oil weight. A yield of about $97.7 \%$ of biodiesel from jatropha oil by transesterification reaction on bench scale was obtained. The lower layer was treated with phosphoric acid and the glycerol of $85 \%$ purity was collected, as well as the free fatty acids and the sodium phosphate. These results were presented in Table 2. The most important biodiesel parameters were determined and reported in Table 3.

\section{Biodiesel production through pilot plant}

Biodiesel was produced from $100 \mathrm{~kg}$ jatropha oil in the pilot plant. The process flow chart accompanied with a material balance is represented in Fig. 2.

\section{Biodiesel yield}

The biodiesel yield was estimated after the reaction, collection from the upper layer of the decanter and methanol removal. The produced biodiesel weight relative to the initial used jatropha oil was taken as the biodiesel yield. Theoretically, if

Table 2: Bench scale experiment products quantities

\begin{tabular}{lc}
\hline Products & Quantity (g) \\
\hline Biodiesel & 1954 \\
Glycerol (85 \%) & 230 \\
Free fatty acids & 40 \\
Sodium phosphate & 26 \\
\hline
\end{tabular}

$100 \mathrm{~kg}$ of triglycerides react with $10 \mathrm{~kg}$ of methanol, theoretical results should be $100 \mathrm{~kg}$ of biodiesel and $10 \mathrm{~kg}$ of glycerol. However, two possible side reactions may take place in the transesterification reaction, neutralization of the free fatty acids of the vegetable oil and/or saponification of the triglycerides. Both of them produce sodium soaps and, therefore, reduce the biodiesel yield. Neutralization of the free fatty acids could occur since the acid value of the used vegetable oil was about $1 \mathrm{mg} \mathrm{KOH/g}$. Saponification of triglycerides could be in a minimal value since the water content of the used vegetable oil was nil, but presence of the hydroxide group may cause triglycerides saponification. As shown in Fig. 2a biodiesel yield of 97.6 wt \% was obtained from transesterification of $100 \mathrm{~kg}$ jatropha oil and methyl alcohol with sodium hydroxide as catalyst. Some of the produced biodiesel properties were measured and presented in Table 3.

\section{Glycerol purification}

The glycerol layer was collected from the bottom of the decanter. This layer contained the glycerol, part of the unreacted methanol, formed soaps and the catalyst. Phosphoric acid was added to this layer to neutralize the catalyst and convert soaps back to free fatty acids. Three distinct layers were separated with free fatty acids on the top, glycerol and methanol in middle and sodium phosphate on the bottom. Free fatty acids and sodium phosphate were collected and sent to each corresponding storage tank. The methanol was then recovered by about $85 \%$ by heating the glycerol above $65^{\circ} \mathrm{C}$ in a closed loop and sent to the methanol storage part as shown in Fig. 2. The produced glycerol was $85 \%$ purity according to the HPLC analysis and could be used in industrial uses or exposed to further purification for pharmaceutical uses. Free fatty acids of $2 \%$ of the oil weight are obtained, as well as sodium phosphate salts. These free fatty acids could be used

Table 3: Fuel properties of produced jatropha biodiesel compared to petroleum diesel

\begin{tabular}{lccc}
\hline \multicolumn{1}{c}{ Property } & Bench scale & Jatropha biodiesel & \\
& Pilot scale & Diesel \\
\hline Viscosity at $20^{\circ} \mathrm{C}(\mathrm{m}$ pas.s) & 5.01 & 5.20 & $3-5$ \\
Flash point ${ }^{\circ} \mathrm{C}$ & 160 & 162 & 68 \\
Pour point ${ }^{\circ} \mathrm{C}$ & -9 & -6 & -20 \\
Cloud point ${ }^{\circ} \mathrm{C}$ & 6 & 0 & - \\
Carbon residue (\% wt.) & Nil & Nil & 0.17 \\
Acid value (mg KOH/g) & 0.26 & 0.30 & - \\
Calorific value (M J/kg) & 40.59 & 39.44 & 42 \\
\hline
\end{tabular}


Int. J. Environ. Sci. Tech., 6 (2), 219-224, Spring 2009

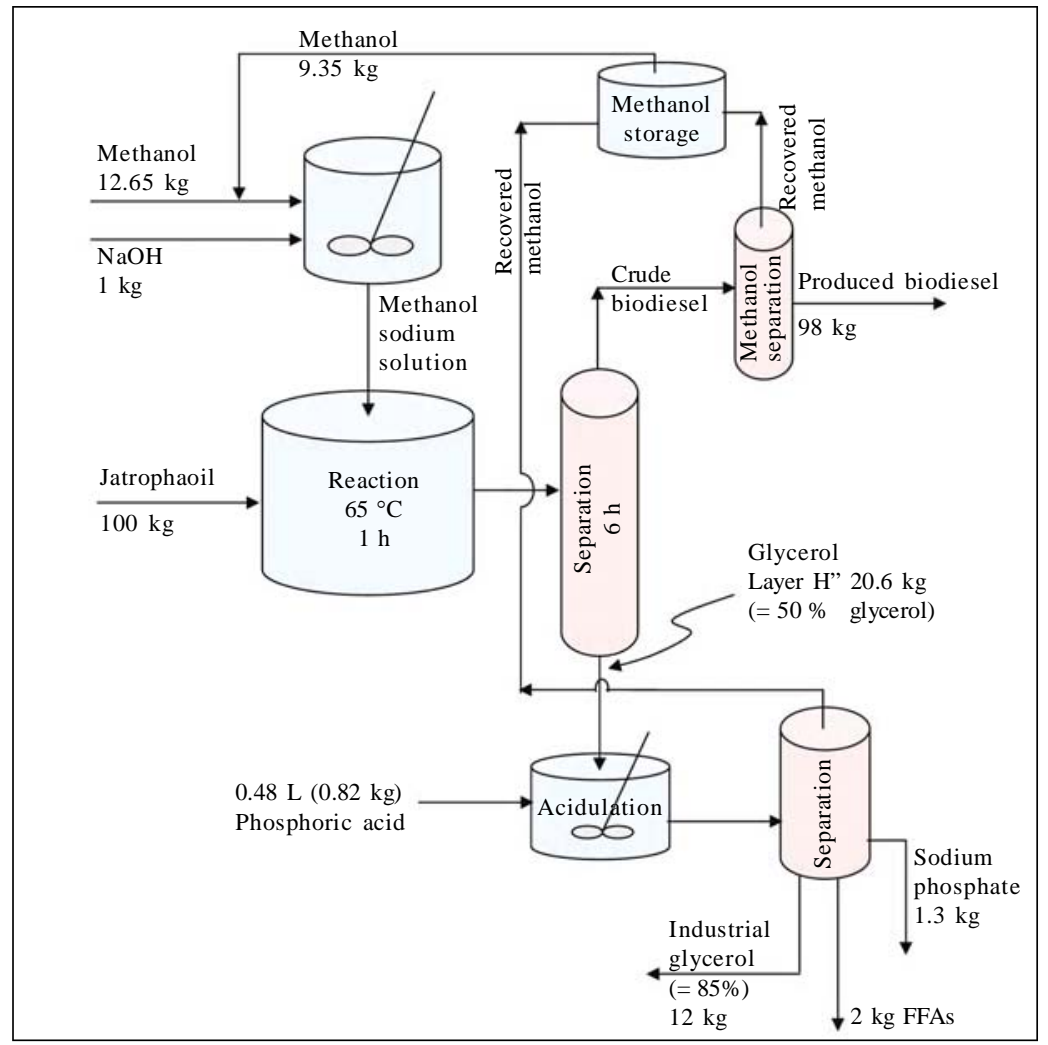

Fig. 2: Pilot scale material balance for Jatropha oil transesterification using $\mathrm{NaOH}$ (1\%) as catalyst

in some industries such as soap manufacturing. Sodium phosphate salts also have valuable uses as a source of sodium and/or phosphate.

\section{Biodiesel evaluation}

Some of the most important chemical and physical quality control parameters of the produced biodiesel on both bench and pilot scales are measured and compared with the petroleum diesel parameters and presented in Table 3. These parameters such as viscosity, flash point, pour point, cloud point, carbon residue, acid value and calorific value have acceptable values and are in agreement with the petroleum diesel parameters.

\section{CONCLUSION}

Jatropha oil has been chosen as a feedstock for biodiesel production since it is non-edible oil; in addition to the success of its cultivation overall Egyptian desert. Studies of biodiesel production from jatropha oil by transesterification on both bench and pilot scales have been developed and evaluated. Physical and chemical properties of produced biodiesel are in agreement with those of petroleum diesel and with international standards of biodiesel. Valuable byproducts such as glycerol, free fatty acids and sodium phosphate are produced. A biodiesel yield on pilot scale nearly to $98 \%$ with quality agreement with petroleum diesel enable transfer the process to industrial scale up.

\section{ACKNOWLEDGMENTS}

Financial support from US-Egypt Joint Research Grant is appreciated. Also Petroleum Institute at Nasr city, Egypt is gratefully acknowledged for biodiesel specifications determination.

\section{REFERENCES}

Alptekin, E.; Canakci, M., (2008). Characterization of the key fuel properties of methyl ester-diesel fuel blends. Fuel, 88 (1), 75-80 (6 pages).

Antolin, G.; Tinaut, F. V.; Briceno, Y.; Castano, V.; Perez, C.; Ramirez, A. I., (2002). Optimisation of biodiesel production 
by sunflower oil transesterification. Bioresour. Tech., 83 (2), 111-114 (4 pages).

Baldwin, J. D.; Kilmowski, C. H.; Keesy, M. A., (1982). Fuel additives for vegetable oil-fueled compression ignition engines. Vegetable oil fuels. Proceedings of the international conference on plant and vegetable oils as fuels, ASAE, 82 (4), 224.

Boehman, A. L., (2005). Foreword biodiesel production and processing. Fuel Process. Tech., 86 (10), 1057-1058 (2 pages).

Bouaid, A.; Diaz, Y.; Martinez, M.; Aracil, J., (2005). Pilot plant studies of biodiesel production using Brassica carinata as raw material. Catal. Today. 106 (1-4), 193-196 (4 pages).

Dorado, M. P.; Ballesteros, E.; Lopez, F. J.; Mittelbach, M., (2004). Optimization of alkali-catalyzed transesterification of brassica oil for biodiesel production. Energ. Fuel, 18 (1), 77-83 (7 pages).

Encinar, J. M.; Gonzalez, J. F.; Rodriguez-Reinares, A., (2007). Ethanolysis of used frying oils, biodiesel preparation and characterization. Fuel Proc. Tech., 88 (5), 513-522 (10 pages).

Fuls, J.; Hawkins, C. S.; Hugo, F. J. C., (1984). Tractor engine performance on sunflower oil fuel. J. Agri. Eng., 30, 29-35 (7 pages).

Haas, M. J., (2005). Improving the economics of biodiesel production through the use of low value lipids as feedstock: Vegetable oil soapstock. Fuel Proc. Tech., 86 (10) 1087 1096 (10 pages).

Kayasiri, P.; Jeyashoke, N.; Krisangkura, K., (1996). Survey of seed oils for use as diesel fuels. J. Am. Oil Chem. Soc., 73 (4), 471-474 (4 pages).

Knothe, G.; Steidley, K. R., (2005). Kinematic viscosity of biodiesel fuel components and related compounds. Influence of compound structure and comparison to petrodiesel fuel components, Fuel, 84 (9), 1059-1065 (7 pages).

Ma, F.; Hanna, M. A., (1999). Biodiesel production: A review. Bioresour. Tech., 70 (1) 1-15 (15 pages).

Meher, L. C.; Dharmagadda, S. S. V.; Naik, S. N., (2006a). Optimization of alkali-catalyzed transesterification of Pongamia pinnata oil for production of biodiesel. Bioresour. Tech., 97 (12), 1392-1397 (6 pages).

Meher, L. C.; Sagar, D. V.; Naik S. N., (2006b). Technical aspects of biodiesel production by trasesrerification: A review. Renew Sust. Energ. Rev., 10 (3) 248-268 (21 pages).
Peterson, C. L.; Wanger, G. L.; Auld, D. L., (1983). Vegetable oil substitutes for diesel fuel. T. ASAE, 26, (2), 322-327 (6 pages).

Phan, A. N.; Phan, T. M., (2008). Biodiesel production from waste cooking oils. Fuel, 87 (17-18), 3490-3496 (7 pages).

Ryan, T. W.; Dodge, G.; Callahan, T. J., (1984). The effects of vegetable oil properties on injection and combustion in two different diesel engines. J. Am. Oil Chem. Soc., 61, (10) 1610-1619 (10 pages).

Saifuddin, N.; Chua, K. H., (2004). Production of ethyl ester (biodiesel) from used frying oils: Optimization transesterification process using microwave irradiation. Malaysian J. Chem., 6, (1) 77-82 (6 pages).

Schlautman, N. J.; Schinstock, J. L.; Hanna M. A., (1986). Unrefined expelled soybean oil performance in a diesel engine. T. ASAE, 29 (1), 70-73 (4 pages).

Srivastava, A.; Prasad, R., (2000). Triglycerides-based diesel fuels. Renew Sust. Energ. Rev., 4 (2), 111-133 (23 pages).

Tiwari, A. K.; Kumar, A.; Raheman, H., (2007). Biodiesel production from jatropha oil (Jatropha curcas) with high free fatty acid: An optimized process. Biomass Bioenerg., 31 (8) $569-575$ (7 pages).

Tomasevic, A. V.; Siler-Marinkove, S. S., (2003). Methanolysis of used frying oil. Fuel Process. Tech., 81 (1), 1-6 (6 pages).

Van Der Wat, A. N.; Hugo, F. J. C., (1982). Attempts to prevent injector cooking with sunflower oil by engine modifications and fuel additives. Vegetable Oil fuels, Proceedings of the international conference on plant and vegetable oils as fuels, ASAE, 82 (4) 230.

Van Gerpen, J., (2005). Biodiesel processing and production. Fuel Proc. Tech., 86 (10), 1097-1107 (11 pages).

Vicente, G.; Martinez, M.; Aracil, J., (2004). Integrated biodiesel production: A comparison of different homogeneous catalysts systems. Bioresour. Tech., 92 (3), 297-305 (9 pages).

Wan Nik, W. B.; Ani, F. N.; Masjuki, H. H., (2005). Thermal stability evaluation of palm oil as energy transport media. Energ. Convers. Manage., 46 (13-14), 2198-2215 (18 pages).

Wang, Y.; Ou, S.; Liu, P.; Xue, F.; Tang, S., (2006). Comparison of two different processes to synthesize biodiesel by waste cooking oil. J. Mol. Catal. A-Chem., 252 (1-2), 107-112 (6 pages).

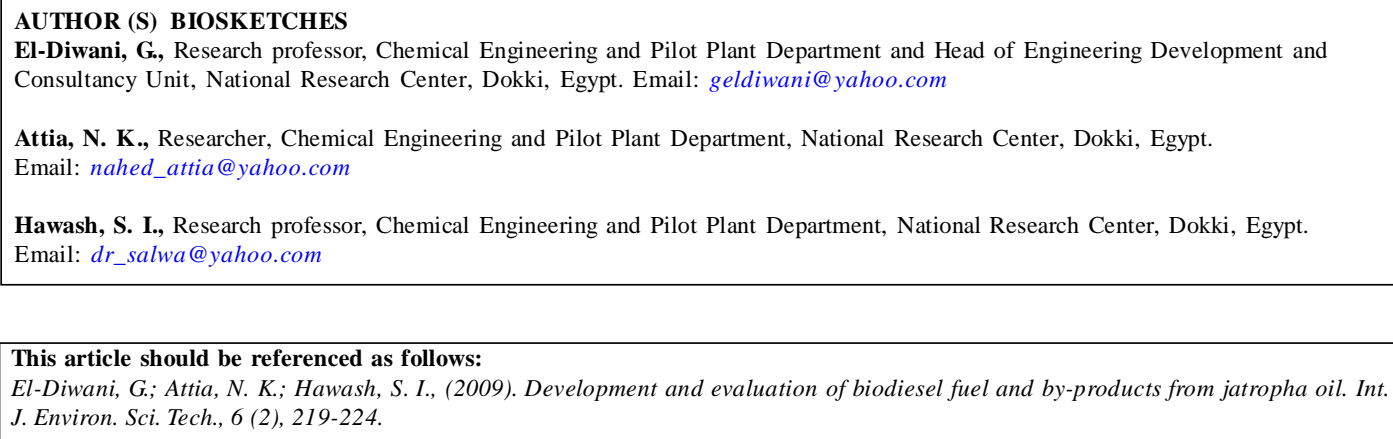

El-Diwani, G.; Attia, N. K.; Hawash, S. I., (2009). Development and evaluation of biodiesel fuel and by-products from jatropha oil. Int. J. Environ. Sci. Tech., 6 (2), 219-224. 